\title{
Bioética, violência e desigualdade: as biociências e a constituição do biopoder
}

\author{
Hélder Boska de Moraes Sarmento \\ Universidade Federal de Santa Catarina (UFSC)
}

\section{Bioética, violência e desigualdade: as biociências e a constituição do biopoder}

Resumo: A sociedade contemporânea está atravessada por contradições e paradoxos, dentre os quais vale destacar a relação entre a alta tecnologia e, a pior situação humana, a miséria. Resultado das escolhas éticas e políticas desta era tecnológica, vive-se em situações de fronteira, nas quais as biociências desempenham papel central, tanto no volume de conhecimentos gerados, como na utilização de seus resultados, que, sem controle social, ampliam desigualdades. O objetivo deste artigo é demonstrar o quanto as biociências articulam-se com o desenvolvimento científico dos países inovadores de tecnologia, criando uma nova relação de poder, violento e desigual para os que apenas a consomem, denominado de biopoder. Daí a necessidade de uma bioética crítica capaz de empreender reflexões sobre os procedimentos técnicos, os fundamentos da atividade científica, sua aplicabilidade e relação com o mercado, oportunizando uma 'ponte' na tomada de decisões para que a própria ciência não se torne um obstáculo à democracia.

Palavras-chave: violência, desigualdade, biopoder, bioética.

\section{Bioethics, Violence and Inequality: the Biosciences and the Conquest of Biopower}

Abstract: Contemporary society is rife with contradictions and paradoxes, among which stand out the relationship between high technology and the worst human situation, poverty. The result of ethical and political choices of this technological era, we experience frontier situations, in which the biosciences play a central role, both in the volume of knowledge generated, as well as in the use of their results which, without social control, broaden inequalities. The objective of this article is to demonstrate the degree to which the biosciences are articulated with the scientific development of the countries that innovate technologies, creating a new relationship of power, which is violent and unequal for those who only consume, denominated biopower. This creates a need for a critical bioethics that is capable of reflecting on the technical procedures, the bases of scientific activity and their applicability and relation with the market, creating the opportunity for a "bridge" in decision making so that science does not become an obstacle to democracy.

Key words: violence, inequality, biopower, bioethics. 


\section{Notas introdutórias}

Afirma-se que as sociedades contemporâneas tornam-se cada vez mais complexas e contraditórias; convive-se cotidianamente com a sensação de crise e, concretamente, tem-se, por todo lado, situações paradoxais, onde a mais avançada tecnologia está ao lado da pior situação humana, a da miséria.

Essa sensação de crise é expressão do processo civilizatório, daquilo tudo que o homem teve condições de construir historicamente, constituindo sua humanização. Porém, o resultado das conquistas que se acumularam em torno desta humanização - de um projeto de modernidade -, na perspectiva da emancipação humana, tendo a ciência como protagonista, não se realizou em sua radicalidade.

Esse projeto de modernidade tendo o homem como fim e a felicidade como meta de realização foi abalado completamente pelas diferentes formas de desigualdade que se consolidaram. A idéia de 'universalidade' que se colocava para além das barreiras nacionais, culturais e étnicas, tem sido abatida por particularismos e fundamentalismos, assustando a todos, seja por um terrorismo de grupos que disputam um poder soberano; seja por um terrorismo de Estado que, tendo um poder soberano, realiza manobras violentas em todas as instâncias, esferas e locais do mundo globalizado. Outro marco deste projeto, é a 'individualidade', reconhecida pela condição histórica do sujeito e por sua capacidade de escolha moral (apresentada como superação de um sujeito abstrato, centrado na perfectibilidade essencial da pessoa humana), hoje, submetido à condição de objeto de um mercado que o conforma à condição de consumidor passivo e satisfeito, que se resume ao incontrolável desejo de comprar. A concepção de 'autonomia', que capacita seres humanos a pensar, a fazer escolhas racionais e éticas, articuladas a um espaço público, ao trabalho e aos bens necessários à vida, está cada vez mais deteriorada pelo volume de ofertas, que inibem a razão e a moralidade pública, seja pelo reencantamento do mundo da indústria mística; seja pela política negada pelos marqueteiros de plantão; seja pelos rumos da economia que têm levado a maioria da população à pobreza absoluta. No dizer de Rouanet (1993, p. 9):

O projeto civilizatório da modernidade entrou em colapso. Não se trata de uma transgressão na prática de princípios aceitos em teoria, pois nesse caso não haveria crise de civilização. Trata-se de uma rejeição dos próprios princípios, de uma recusa dos valores civilizatórios propostos pela modernidade. Como a civilização que tínhamos perdeu sua vigência e como nenhum outro projeto de civilização aponta no horizonte, estamos vivendo literalmente, num vácuo civilizatório. Há um nome para isso: barbárie. Pois o bárbaro, sem nenhum juízo de valor, no sentido mais neutro e mais rigoroso, é aquele que vive fora da civilização.

Esta condição é resultado de nossas escolhas sociais, políticas, técnicas e éticas, pois iniciamos o século 20 acreditando na ética da ciência e passamos ao novo século - 21 - clamando por uma ciência ética. Se vislumbramos um campo infindável de possibilidades de desenvolvimento e inovação tecnológica, ao mesmo tempo, vemos um conjunto de necessidades humanas básicas sendo negligenciado, com a mais absoluta naturalização, convertendo a desigualdade em processo natural, inevitável do mundo globalizado.

Neste sentido, é importante destacar que o capitalismo (como modo de organização das relações de produção) é uma invenção ocidental particular quese globalizou e se objetivou pelo poder político regulado pelos grupos privados dominantes que ocuparam o Estado e ainda exercem o poder. Isto quer dizer que o capitalismo não é um paradigma ético universal, e muito menos suas expressões, tendências e estratégias para superar as suas próprias crises são a única alternativa. Aliás, é nessa idéia - tão absurda quanto propalada - que o neoliberalismo nos quer fazer crer, a da intransigente defesa do mercado como valor central das relações econômicas e sociais (TEIXEIRA; OLIVEIRA, 1996). É importante a cautela e a crítica, pois esta crença pode se tornar um pensamento único, talvez até uma teologia, como querem alguns.

Assim, não há uma globalização e sim globalizações em curso, nas diferentes esferas, do ensino, da ciência e inovação, da produção, da economia, da cultura etc. É importante lembrar, se existe desigualdade dentro de uma cultura ela tende a ser ainda maior entre culturas, objetivada tanto pelo poder econômico como pelo poder simbólico.

Podemos dizer que a desigualdade não é um fenômeno novo. Porém, assume características peculiares no desenvolvimento capitalista dada à própria natureza de apropriação e acumulação que este sistema exige. A desigualdade social começou a carac- 
terizar nossas sociedades democráticas muito antes da globalização, da tirania dos mercados financeiros, do sistema monetário europeu e 20 anos antes do Tratado de Maastricht (conhecido como Tratado da União Européia, assinado em 1992).

O que é novo refere-se à dimensão e à relevância que lhe são atribuídas nos dias de hoje, tanto pela sua amplitude (horizontalidade), quanto pela sua profundidade (verticalidade). A desigualdade não é apenas sinônima de pobreza, de precariedade econômica e material (perda da capacidade de consumo), mas também cultural e simbólica. É o caso do próprio indivíduo que, não sendo mais reconhecido como sujeito e tendo reduzido as suas possibilidades de estabelecer planos e projetos de vida fora dos circuitos das relações imediatistas da cotidianidade do mercado, tornou-se também um 'homem sem qualidade' (MARTINS, 2008, p. 12).

Faz-se, então, prioritário o conhecimento e o debate sobre os desdobramentos da globalização e da desigualdade, não apenas para compreendê-los, mas, principalmente para movimentar-se em seu interior. Esta perspectiva implica voltar o olhar para o futuro, onde a compreensão crítica do presente poderá significar a ampliação das possibilidades de melhoria da qualidade de vida de muitos.

Diante deste quadro expressivo da globalização/ desigualdade, não é tão simples pensar, hoje, em mecanismos alternativos de acesso à riqueza socialmente produzida. Mais ainda, com este assustador crescimento do contingente de seres humanos impossibilitados de prover sua subsistência por meio de formas tradicionais de acesso à riqueza, a desigualdade crescente, faz também, crescer a violência.

A partir dessas referências, podemos compreender a direção que a globalização do capitalismo tem tomado no acirramento das desigualdades. Trata-se de um direcionamento construído ou produzido por um conjunto de decisões políticas e econômicas que reverberam em diferentes áreas da vida social, com implicações e conseqüências diretas sobre o cotidiano de vida dos indivíduos, destaque-se o caso das biociências.

\section{As biociências e a constituição do biopoder}

Compreende-se as biociências como o conjunto das ciências que vem desenvolvendo pesquisas e experiências, utilizando como referência a matéria viva dos seres. Esta matéria viva, no dizer de Joly (1995, p. 197) “[...] têm sua fonte no jardim íntimo do vivente (o conhecimento e o domínio do código genético) [...].", são os recursos genéticos, por isso as chamadas biotecnologias, bioengenharias etc. A expressão recursos genéticos abrange o conjunto das formas vivas suscetíveis de serem utilizadas para criar novas variedades de plantas, de raças de animais ou de camadas de microorganismos, incluindo agora também a genética humana.

O que salta aos olhos da sociedade a partir destas pesquisas e experiências é o seu dinamismo e, mais ainda, a renovação completa e permanente dos equipamentos e suportes técnicos nesta área, ampliando suas possibilidades e abrindo novas perspectivas. O que tem gerado também incertezas quanto ao seu futuro e o da própria relação homem-natureza-sociedade.

A questão central aqui colocada, no campo das biociências, mais do que o crescimento rápido dos resultados científicos é o seu uso, muitas vezes supervalorizando seu potencial ou subestimando a necessidade de controle sistemático de suas experiências e aplicações e seus impactos na vida dos indivíduos e da sociedade.

Os desdobramentos desta questão, por mais óbvio que pareça, passam pelas diferenças científicas e tecnológicas entre o norte e o sul, levar isto em consideração é muito importante, pois abriga repercussões sociopolíticas significativas neste mundo globalizado, muitas vezes denominado de sociedade do conhecimento.

Segundo estimativas da Organização das Nações Unidas para a Educação, a Ciência e a Cultura (Unesco), três quartos dos cerca de 110 milhões de engenheiros, cientistas e técnicos, que constituem o potencial científico e tecnológico, neste final de século, estão concentrados nos países desenvolvidos, que por sua vez, somam apenas um quarto da população mundial (JOLY, 1995).

Estas diferenças têm variações enormes, quanto aos recursos humanos, aos recursos materiais e à própria visibilidade e aplicabilidade dos trabalhos de pesquisa. Mas o que chama a atenção é que a maior parte das necessidades vitais dos países do sul (saúde, agricultura, alimentação, educação) está relacionada com áreas de pesquisa que não podem ser simplesmente transportadas e adaptadas dos países do norte. Ainda, em vários países do sul são privilegiadas pesquisas sobre culturas rentáveis, comprometendo as necessidades de sua própria população ou dos próprios pesquisadores, que ficam presos às prioridades definidas pelo setor público e/ou privado e nem sempre estão voltadas para o interesse comum. Ao mesmo tempo, os países do norte buscam desenvolver pesquisas e tecnologias para não dependerem mais dos países do sul. Esta complexa e contraditória relação, de difícil apreensão, é significativa, pois amplia o fosso da desigualdade existente entre o norte e o sul, com desdobramentos éticos e políticos sempre alarmantes.

Com esse conjunto de características, a dominação política e econômica sobre o desenvolvimento científico e tecnológico dos países do norte sobre os países do sul é gritante, inclusive porque também passam a induzir as políticas de fomento e incentivo em todo o mundo. 
Considerando-se que a ciência não é atemporal e sim um produto social, parece que seu desenvolvimento tecnológico, pelos países ricos, vem dando as costas ao seu sentido. Segundo Calame (1995, p. 176),

[...] à ética do conhecimento deve agora somar-se uma ética da sobrevivência e do desenvolvimento, que hierarquize as pesquisas a empreender em função dos objetivos maiores da humanidade e forneça um código de comportamento dos governos, e uma ética da tradição e do devir, que nos obrigue a nos interrogarmos sobre os riscos de que a pesquisa perturbe as sociedades.

Os grandes desafios colocados à ciência, no início do século 20, como desnutrição, diarréias infecciosas, malária e doenças respiratórias, continuam a perdurar diante de tecnologias sofisticadíssimas, requisitadas e desenvolvidas para as guerras. Complexidade e simplicidade alternam-se nas lógicas sociais, econômicas e políticas do século 21 . O homem vive hoje cercado de ambigüidades, contradições e paradoxos e, por que não, desigualdades, expressadas por novas formas de violência.

Desta maneira, pode-se compreender como as biociências articulam-se diretamente com o desenvolvimento tecnológico de ponta, dos países industrializados, criando uma nova relação de poder excludente e desigual na medida em que os resultados destes avanços estão direcionados para os próprios países. É a isto que denominamos de biopoder, isto é, o poder oriundo do domínio de conhecimento gerado pelas biociências e conseqüentemente do controle das biotecnologias. A forte ideologia da competência técnico-científica, antes restrita a técnicos, é reconfigurada, agora representada pelas grandes organizações de desenvolvimento científico-tecnológico, com seus pesquisadores profissionais, redistribuindo novas formas de poder: o conhecimento, a informação e o mercado futuro (SARMENTO, 2005).

$\mathrm{O}$ biopoder desenvolve uma relação ético-política complexa, pois implica um grande desafio humanitário, definido pela articulação entre a esfera institucional de ação com a esfera social dos interesses individuais e coletivos. Isto fica claro, quando olhamos para as sociedades e identificamos as várias faces da pobreza que persistem, quando, objetivamente, o compromisso ético poderia ao menos reduzi-la, se, para isso, houvesse interesse (KOTTOW, 1995).

O biopoder também apresenta uma relação complexa entre o poder institucional, através das organi- zações (públicas e privadas) que o sustentam, e o poder político que se mostra pela força e capacidade de dirigir a vida social dos homens. Seu fazer cotidiano, para além dos laboratórios, é a contraditória relação existente entre os interesses e disputas do mercado com os interesses públicos da sociedade.

O grande intermediador desta relação biociências versus biotecnologias vem sendo o dinamismo econômico das grandes indústrias que mobilizam seu capital financeiro para criar o capital de conhecimentos científicos e técnicos. Desta forma, pode-se perceber uma alteração na lógica do avanço dos conhecimentos, que passa a ser determinada pelas patentes e daí para a garantia de mercados atuais e futuros, o que acaba por criar barreiras contra a difusão dos conhecimentos e o acesso à inovação.

A ciência torna-se 'toda poderosa' pela maneira como se configura em poder econômico, materializada nas patentes, que produzem capital humano, capital de conhecimentos, capital de produtos e capital financeiro, gerando mais poder e, com sua conseqüente apropriação, uma nova forma de violência, com uma dimensão ainda maior de desigualdades.

Portanto, o poder das biociências e das biotecnologias torna-se, hoje, um biopoder, tanto pela sua concentração econômica, quanto pela sua centralização de conhecimentos, restrita àqueles poucos que têm acesso a este 'capital'.

Acreditamos que este 'capital' difere da idéia de 'bem', pois este último, não significa a liberação e apropriação inconseqüente de pesquisas para a construção de um novo homem geneticamente modificado ou economicamente desconfigurado. A idéia de 'bem' não está na apropriação particular do 'capital', mas na definição de critérios claros, transparentes e públicos, para os quais o homem é o valor central. O 'bem' o qualifica, integra e humaniza, jamais fragmenta, divide ou violenta.

É importante considerar, ainda, que no sentido jurídico 'bem' é tudo aquilo que é objeto de direitos, sejam materiais ou imateriais, tangíveis ou intangíveis, tendo os homens o direito e o dever de participar desse processo. Ainda mais, pelo fato de que, na sociedade capitalista, os bens foram transformados em mercadorias, portanto, suscetíveis de compra e venda, atribuindolhes determinado poder pelo que valem economicamente, como é o caso específico das biociências.

Isso coloca em causa não apenas a apropriação ou a posse desses bens, mas também a disposição de 
poderes na sociedade sobre os indivíduos. Assim, os conhecimentos que se produzem sobre a natureza sociobiológica do homem não podem ser de domínio privado, pois o são de interesse comum, público. Devem ser administrados, ou geridos como do interesse comum, e organizados de tal maneira que esta gestão - pública, comunitária - conte com a participação direta dos interessados.

O que se percebe é que a prática das biociências tem sido desenvolvida e apropriada por grupos privados, sendo seu conhecimento e produto não informados à opinião pública, comprometendo, portanto, a dimensão ético-política de emancipação humano-social, ou seja, a justiça, a eqüidade e a igualdade.

Portanto, se o direito ao conhecimento, à informação e aos resultados das pesquisas é cada vez mais restrito, na mesma proporção, o direito à participação política vai restringindo-se. Seria a ciência, e em particular as biociências, hoje, uma nova forma de violência, um obstáculo à democracia?

\section{Violência e desigualdade: a bioética crítica como possibilidade na construção da democracia}

Sem qualquer dúvida, a ciência já é uma mercadoria, pois se tornou um bem intermediário, de importância estratégica, vital para o futuro econômico. $\mathrm{O}$ poder gerado pelas biociências, cada vez menos distribuído e mais concentrado àqueles que têm condições econômicas de obtê-lo, é também uma expressão material da economia. Observando-se que democracia não é mercadoria, e, sim, construção sociopolítica, sempre que esta dimensão é sacrificada, comprometem-se seu processo, seus resultados.

Vale destacar que as biociências não são aqui consideradas com o poder de substituir as forças produtivas ou por si só democratizarem as sociedades, mas indicar que as possibilidades que se desdobram, são significativas, não devendo ser menosprezadas.

Isto já está muito bem demarcado na disputa acirrada entre os EUA, a Europa e o Japão, que, sozinhos, dominam quase a totalidade dos grandes sistemas estratégicos, fazendo disto uma guerra econômica violenta, com conseqüências na competição e na influência sobre a ciência e a tecnologia. Isso implica diretamente em um claro limite para os países do terceiro mundo, que depositavam esperanças em ampliar as possibilidades de superação de seus problemas, com os resultados da ciência e tecnologia. Além de estes resultados serem insatisfatórios, vive-se cada vez mais uma marginalização, dentro do sistema econômico mundial. No dizer de Callon (1995, p.397),

[...] essas polêmicas ajudam a questionar a própria idéia de uma ciência independente, acessível a to- dos e portadora de luzes e de progresso. O caráter público da ciência é agora o resultado de um cálculo estratégico que ousa dizer seu nome: a informação é posta em circulação, pois se torna uma moeda de troca. Se acrescentarmos a isso a tomada de consciência da inutilidade prática da ciência fundamental que, para converter-se em progresso econômico, precisa de imensos investimentos em termos de capital e de formação, podemos avaliar a crise que abala a instituição científica. O rei está nu: o conhecimento científico mais fundamental revela-se inextricavelmente misturado aos interesses privados e se torna cada vez menos sinônimo de bem geral e de razão universal.

Nessa complexa e contraditória condição, em que se encontram as instituições e o próprio conhecimento científico, é que as discussões éticas têm emergido, embora ainda centralizadas nos procedimentos técnicos e não nos fundamentos da atividade científica e da aplicabilidade dos produtos dessa ciência.

Cada vez mais se faz urgente que a sociedade redefina suas relações com a ciência e com as organizações que a financiam e produzem, buscando romper com os monopólios deste saber, através de mecanismos éticos de controle social. Acredita-se seja possível criar mecanismos éticos que nos levem da atual condição de lucros privados da ciência para a sua responsabilidade social.

As biociências não se tornaram essa realidade complexa por conta própria ou como obra do acaso. Também, não se constituem de uma linha tênue entre ficção e realidade de difícil apreensão. São resultado da própria ação dos homens que a fazem e a vivem, tem, portanto, condição de redefinir sua direção e de reconstruir seu percurso.

Assim, passa a ser fundamental que as biociências resgatem sua função social e responsabilidade social, contribuindo para reconstruir, a partir de agora (respondendo imediatamente ao grave quadro de desigualdade e violência expresso nas faces da miséria, fome e doenças), o futuro da sociedade humana.

Diante desta condição é que a ética vem ocupando um papel importante, recuperando sua relação com a política e a moralidade da vida pública diante deste mundo competitivo, voltado ao sucesso absoluto, ao lucro e ao poder do consumo. Esta politização da ética repercutiu em nossas individualidades - mesmo representando um sentimento dúbio e às vezes ambíguo de esperança e desesperança, de certeza e incerteza, de felicidade e angústia, confiança e desconfiança - e, também, implicou um movimento social mais amplo, de grande estatura política, clamando por uma sociedade solidária, democrática e justa. Este movimento traz que é possível mudar e realizar nossos sonhos, ultrapassando o isolamento, o individualismo, construindo uma convivência coletiva em 
novas bases, com novos valores, sendo um deles fundamental, o da democracia.

Para além desta politização da ética, indicamos o quanto as descobertas científicas e tecnológicas, que irrompem dos 'tubos de ensaio' e saltam para a vida cotidiana, precisam ser discutidas, posição que a bioética vem assumindo. Pois, os desenvolvimentos científicos e tecnológicos, apresentados pelas biociências, fizeram com que a chamada bioética correspondesse a uma nova estratégia, para construção da ética nas ciências. Desta maneira, a bioética vem se compondo, tanto por movimentos de diferentes setores, como em formas de organização nas mais diversas instituições, através de comitês públicos, permanentes ou com objetivos definidos, para posicionarem-se sobre as novas questões emergentes.

É neste espaço e com a perspectiva de construir outro sentido que a bioética vem alimentando um repensar destas práticas ético-políticas, através de uma ampliação do diálogo, entre as diversas áreas, para enfrentamento das relações que constituem o mundo contemporâneo, principalmente entre ciência e sociedade.

A bioética não pode ser considerada como uma área de especialização deslocada da vida cotidiana, ao contrário, seu avanço pode subsidiar novas lutas por mais direitos sociais, portanto, não há mais como ignorar este saber que se impõe, construindo o novo e nos chamando para enfrentá-lo, quiçá, direcionálo. Isto é, no dizer de Pegoraro (1998, p. 56), a bioética

[...] está situada em um amplo contexto científico e sociopolítico, podendo ser entendida como o debate sobre as recentes descobertas tecnocientíficas da biologia, biofísica, bioquímica, genética e das ciências médicas, que levantam novos problemas às ciências humanas dos valores éticos, das convicções milenares de pessoas, de escolas filosóficas, teológicas e jurídicas que tratam do sentido da vida e da morte, da convivência política e da relação da natureza com o homem.

Nessa perspectiva, a bioética é compreendida como um lugar-comum entre a ciência e a simbologia (no sentido de explicar e esclarecer o sentido das coisas) podendo constituir-se como um novo marco para a renovação dos estudos éticos, dando-lhes maior concretude, por estar vinculado diretamente aos problemas reais da vida sem abstrair das raízes filosóficas, religiosas, políticas e jurídicas, ou seja, favorecendo uma convergência entre teorias e práticas cotidianas.

É deste ponto que se entende a necessidade de um amplo diálogo político entre os cientistas e a sociedade, pois o desenvolvimento científico-tecnológico deve estar a serviço da vida, do ser humano, do meioambiente e não ao contrário.
Se nesse contexto, esta violenta inversão (do homem e de suas relações a serviço da tecnociência) torna-se uma ameaça real, o homem é colocado diante de um impasse, manifestado como um estado de 'vazio', um mal-estar ético e político. Diante deste e para seu enfrentamento, Garrafa (1994, p. 349), citando o filósofo Hans Jonas nos fala do princípio da radicalidade, lembrando que o problema central da bioética não é o do 'limite ético', mas aquele das razões que justificam um dado juízo moral. Sendo que esta radicalidade também tem que ser aplicada à democracia, substituindo esta enganosa, que aí está, por uma verdadeira democracia social. Nesta direção, ele nos aponta que o progresso moral coletivo pode ser evidenciado das seguintes formas: a) através da legislação dos Estados modernos, b) em certos valores que são incorporados nos códigos das leis; c) nos comportamentos públicos. Talvez, destes três, o comportamento público seja o mais difícil, pois sua realização está diretamente vinculada à sua experiência e construção. No dizer de Telles (1994, p. 91):

\begin{abstract}
Uma cultura pública democrática é aquela que se abre ao reconhecimento da legitimidade dos conflitos e da diversidade dos valores e interesses demandados como direitos. [...] Os direitos estruturam uma linguagem pública que baliza os critérios pelos quais os dramas da existência são problematizados e julgados nas suas exigências de eqüidade e justiça. [...] Na medida em que são reconhecidos, os direitos estabelecem uma forma de sociabilidade regida pelo reconhecimento do outro como sujeito de interesses válidos, valores pertinentes e demandas legítimas. [...] Isto requer a constituição de espaços públicos nos quais as diferenças possam se expressar e se representar em uma negociação possível, nas quais a dimensão ética da vida social pode se constituir em uma moralidade pública.
\end{abstract}

Este é o desafio que a bioética vem se propondo: uma crítica da moral estabelecida. Se considerarmos a democracia como a possibilidade de praticar a convivência com as diferenças, vemos a própria sociedade capitalista contemporânea fazendo-nos acreditar que a verdade está na consolidação da desigualdade, como uma auto-justificativa de sua própria condição, inevitável, natural, constitutiva do próprio homem.

Pode-se identificar que a bioética enuncia um movimento do próprio homem, insatisfeito com seus próprios feitos, voltando-se para o seu dever-ser, para o seu futuro, por mais distante que este possa estar. Ao mesmo tempo, em que a desigualdade se naturaliza e a violência é ampliada, vemos homens, mulheres e crianças em luta, se não por uma causa (como movimento consciente), mas pelas suas próprias vidas, rompendo com a naturalização da miséria, da 
fome, do medo, da doença. Demonstrando assim que a vida pulsa, que a busca de uma nova vida se faz para além dos laboratórios, dos testes biológicos, dos determinismos econômicos. Se o homem está se refazendo pela reorganização biológica, ele também se refaz permanentemente pela vida social e cultural, são caminhos diferentes de um mesmo homem.

É condição humana a construção do homem, sua liberdade e responsabilidade, a forma como se organiza e imprime sentido à vida, que, ao mesmo tempo em que é portadora do belo/bom/útil/verdadeiro, traz, em si, o feio/mal/inútil/falso, ou a insegurança, pela possibilidade da destruição de sí próprio.

Conhecer estes mecanismos, seus efeitos e sistemas faz-se imprescindível, pois não se pode aceitar passivamente os resultados das biociências como leis ou regras para o comportamento humano. Torna-se fundamental conhecer estas novas estruturas de poder, suas novas formas de violência, que interferem em nossas ações e vidas, para sabermos para onde estamos indo e se é isto que queremos.

É justamente neste ponto que a bioética tem sido chamada, pois este conhecimento não está restrito aos pesquisadores que desenvolvem suas análises, ensaios ou produtos. A bioética está exigindo um conhecimento amplo e radical sobre nossas vidas, a partir de variadas angulações, e áreas do conhecimento. O que vale ressaltar é que esta pluralidade, expressa através das diferentes representações sociopolíticas deste conhecimento, implica em perceber suas conseqüências e efeitos sobre o conjunto de nossas vidas.

Além disso, as biociências estão trazendo para as discussões éticas, ou melhor, para a experiência humana, novos fatores, novas situações e circunstâncias que exigem também novos conhecimentos e novas posturas, cuja projeção e coerência ainda não estão definidas. É o próprio questionamento bioético que tem trazido as nossas próprias contradições à tona, mostrando o que estamos fazendo de nossas vidas.

No caso da bioética, não se está apenas lidando com pequenos interesses de grupos políticos divergentes, está-se seriamente discutindo e intervindo na existência humana, na sua natureza genética e, conseqüentemente, sociopolítica.

$\mathrm{Na}$ medida em que vão sendo conquistadas novas possibilidades de interferir nos aspectos físicobiológicos, resultado do desenvolvimento científicotecnológico, ao mesmo tempo, são feitas escolhas históricas que respondem sobre o futuro biológicosocial do homem, portanto, sua dimensão sociopolítica. São circunstâncias recentes a demandar perguntas e respostas que vêm sendo construídas, justamente pela bioética, na busca de clarificar e compreender o fenômeno da vida, trabalhando com alguns referenciais que implicam, com maior ou menor precisão, a relação entre ética, moralidades e vida.
Embora essas pesquisas científicas sejam emergentes, sua diversidade e complexidade já suscitam, entre cientistas e teóricos, divergências e autocríticas, que começam a se fazer presentes no campo das ciências (e das biociências), principalmente, sobre sua pretensa auto-suficiência diante de um mundo natural e de uma realidade social tão complexa.

Isto é relevante, pois a bioética tem se caracterizado como um discurso interdisicplinar, para o qual é importante demarcar a existência de posições diferentes e divergentes, pois " [...] se requer o reconhecimento de que o sujeito, ao fazer ciência, interage com suas circunstâncias, com a rede de seus interesses e com o limite de suas percepções", ou ainda, "comunidades em torno de convicções são inevitáveis" como diz Anjos (2003, p. 458).

O que se pode inferir é que estas diferenças não são meramente teóricas do ponto de vista interpretativo, mas condicionam a vida social, ética e política dos sujeitos envolvidos, pois implicam relações de poder, na medida em que os avanços biotecnológicos estão diretamente articulados às diferentes formas de concentração do poder na sociedade.

É nesta perspectiva que os bioeticistas Giovanni Berlinguer (1993) e Volnei Garrafa (2003), endossados por outros colegas, vêm propondo uma 'bioética dura', ou das 'situações persistentes e emergentes', comprometida e identificada com a realidade dos chamados países em desenvolvimento. Esta perspectiva defende a concepção de que a bioética deixe de ser meramente descritiva ou simplesmente analítica de situações conflitivas para tornar-se um instrumento concreto para a construção de uma sociedade mais democrática, equânime, solidária e comprometida com transformações sociais verdadeiramente inclusivas.

Conforme citado anteriormente, os chamados países periféricos ainda convivem com um conjunto de determinações - marcadas pela desigualdade, concentração de poder político e econômico, inacessibilidade aos grandes desenvolvimentos científicos e tecnológicos, e pelas diferentes formas de violência, entre outras, estas situações persistentes que não podem ser desconsideradas. Esses países periféricos carregam em sua história contradições absurdas, que precisam ser compreendidas na lógica que lhes dá sustentação, a de um capitalismo contemporâneo cada vez mais violento e destrutivo, reafirmando paradoxos éticos insustentáveis.

Porém, simultaneamente, emerge um quadro de situações, em decorrência direta dos grandes avanços científicos e tecnológicos das últimas décadas, tais como, novos medicamentos, transplantes, reprodução humana, clonagem, que não se encontram disponíveis ao conjunto da população.

Reconhecer estas questões é assumir uma posição ética e política clara, tanto do ponto de vista teó- 
rico como prático, é não compactuar com a naturalização destas inaceitáveis e desiguais condições de vida. Este é o ponto de partida para um enfoque bioético crítico que busca compreender as condições de vida (necessidades e realidade da população historicamente situada) como fundamento para instrumentalizar uma intervenção radical na busca da diminuição da injustiça e da iniqüidade. No dizer de Garrafa (2003, p. 37)

Os estudiosos da bioética que trabalham em diferentes contextos sociais, com privilegiados/incluídos e desprivilegiados/excluídos, acabam por ter que enfrentar conflitos e problemas de origens, dimensões e complexidade completamente diferentes. As interpretações dos fatos e as respostas a eles, portanto, não podem ser iguais. Deve-se ter em mente que, entre outras razões, a bioética surgiu para reforçar o lado mais frágil de qualquer inter-relação historicamente determinada. Diante disso, é fundamental que a bioética dos países periféricos, e os da América Latina particularmente, passem a não aceitar mais o crescente processo de despolitização dos conflitos morais. O que está acontecendo, muitas vezes, é a utilização de justificativas bioéticas como instrumentos, como ferramentas metodológicas, que acabam servindo de modo neutral apenas para a leitura e interpretação (acríticas) dos conflitos, por mais dramáticos que sejam. Dessa maneira, é atenuada (e até mesmo anulada, apagada) a gravidade das diferentes situações, principalmente aquelas coletivas e que, portanto, acarretam as mais profundas distorções sociais.

Nesta mesma perspectiva, Anjos (2000, p. 62) chama atenção sobre a bioética, no contexto das desigualdades sociais, ao dizer que é preciso

[...] dar à bioética uma capacidade de análise estrutural, para que se coloque a descoberto a lógica da reprodução da desigualdade na sociedade. Em outros termos, tratar-se-ia de superar uma bioética episódica. Esta desenvolve a tendência de tratar isoladamente as diversas áreas de bioética aplicada, sem perceber as inter-relações entre elas e, sobretudo, sem notar os fatores responsáveis pelas desigualdades. Dessa forma, a bioética se torna facilmente complacente diante de estruturas sociais injustas que reproduzem a má qualidade de vida e a própria morte. E se tornaria criticamente ineficiente para perceber sequer as grandes contradições da vida nos tempos atuais.

Credita-se a estas discussões acerca da bioética uma concepção crítica, pautada não apenas nos desafios contemporâneos resultantes dos avanços científicos e tecnológicos e suas implicações éticas nas dife- rentes áreas de aplicação, mas também na busca de compreender as condições estruturantes das desigualdades. Condições que persistem na realidade, e que, na maioria das vezes, são tratadas com desdém, como se fossem problemas menores não merecedores de preocupação (algumas coletividades seriam menos humanas ou dignas de atenção do que outras?).

O que vale destacar, mais uma vez, é a urgente necessidade de nos situarmos nesse sério e criterioso debate, que transcende o campo acadêmico-científico e se faz presente, cada vez mais, em nossas vidas, ou ainda, na vida futura.

\section{Para concluir}

Os desafios que se colocam sobre as questões discutidas envolvem desde o perigo de posturas fundamentalistas até a ausência de limites éticos no trabalho dos cientistas. É nesse âmbito que a bioética vem se organizando como movimento social e acadêmico, voltada para a compreensão da vida, ou melhor, à formação de uma cultura sociopolítica e técnico-científica, em que a ética da vida seja é absolutamente indispensável para o homem da sociedade contemporânea.

Buscar a aproximação entre ciência-natureza-sociedade implica um movimento amplo, de compreensão, de tomada de decisão e ações, para além do tradicional domínio do homem sobre a natureza. Hoje, o significado é outro, o domínio dos processos vitais que envolvem o homem na sua relação com a natureza, implicam, cada vez mais, a tomada de consciência de sua própria condição como ser natural e social.

Por enquanto, os estudos e descobertas têm apontado que, quanto mais se avança no campo das biociências, mais são identificadas fragilidades teórico-políticas, práticas e científicas. Talvez a mais séria de todas as descobertas seja a de que o ser humano é um ser social e biologicamente inacabado por sua livre escolha. Se o homem transformou-se, pelo seu trabalho, em ser social, superando a condição de ser natural, esta possibilidade, hoje, vai além. Sua condição de ser social permite interferir em sua própria natureza biológica, o que coloca novas condições e perspectivas para compreensão das práticas sociais.

Por mais complexa e contraditória a condição em que se encontrem as instituições/organizações e o próprio conhecimento científico nestes tempos de constituição do biopoder, as reflexões empreendidas pela 'bioética crítica' sobre os procedimentos técnicos, os fundamentos da atividade científica, sua aplicabilidade e relação com o mercado, têm se efetivado como uma 'ponte' para a tomada de decisões (de interesse público) para que a própria ciência não se torne um obstáculo à democracia, ao contrário, seja um caminho viável nessa direção. 


\section{Referências}

ANJOS, M. F. dos. Bioética nas desigualdades sociais. In: GARRAFA, V.; COSTA, S. I. (Org.). A bioética no século XXI. Brasília: UnB, 2000. p.49-65.

. Bioética em perspectiva de libertação. In: GARRAFA, V.; PESSINI, L. Bioética: poder e injustiça. São Paulo: Loyola, 2003, p. 455-465.

BERLINGUER, G. Questões de vida: ética, ciência e saúde. São Paulo: Hucitec, 1993.

CALAME, P. Defesa de uma redistribuição dos saberes. In: WITKOWSKI, N. (Coord.). Ciência e tecnologia hoje. São Paulo: Ensaio, 1995, p.176-178.

CALLON, M. As reestruturações Industriais em torno dos Programas de Pesquisa-Desenvolvimento. In: WITKOWSKI, N. (Coord.). Ciência e tecnologia hoje. São Paulo: Ensaio, 1995, p. 397-399.

GARRAFA, V. Bioética, saúde e cidadania. Humanidades, Brasília, UnB, v. 9, n. 34, 1994.

Loyola, 2003.

; PESSINI, L. Bioética: poder e injustiça. São Paulo:

JOLY, P.-B. Biotecnologias: revolução silenciosa ou encontro frustrado? In: WITKOWSKI, N. (Coord.). Ciência e tecnologia hoje. São Paulo: Ensaio, 1995, p. 197-198.

KOTTOW, M. Bioética y biopolítica. Revista Brasileira de Bioética, Brasília, v. 1, n. 2, 2005.

MARTINS, J. de S. A sociabilidade do homem simples. São Paulo: Contexto, 2008.

PEGORARO, O. Fundamentos filosóficos da bioética. SymposiuM, Recife, Universidade Católica de Pernambuco, v. 1, n. 1, p. 1-18, 1998.

ROUANET, S. P. Mal-estar na modernidade. São Paulo: Companhia das Letras, 1993.

SARMENTO, H. B. M. Bioética, direitos sociais e Serviço Social. Belém-PA: Unama, 2005.

TEIXEIRA, F.; OLIVEIRA, M. (Org.). Neoliberalismo e reestruturação produtiva. São Paulo: Cortez/ UECE, 1996.

TELLES, V. S. Sociedade civil e construção de espaços públicos. In: DAGNINO, E. (Org.) Anos 90: política e sociedade no Brasil. São Paulo: Brasiliense, 1994.
Hélder Boska de Moraes Sarmento

Doutor em Serviço Social pela PUC-SP

Professor do Curso de Serviço Social e Coordenador do Programa de Pós-Graduação em Serviço Social da Universidade Federal de Santa Catarina (UFSC)

\section{UFSC}

Programa de Pós-Graduação em Serviço Social Campus Universitário Reitor João David Ferreira Lima

Trindade - Florianópolis - Santa Catarina CEP: 88010-970 